\title{
COVID-19 and Obesity
}

\author{
Khaja Yaminuddin, $M D^{1}$ (D) Sevil Alkan ${ }^{2}$ (D) and Emine Kübra Dindar Demiray, $M D^{3 *}$ (D) \\ ${ }^{1}$ Taif Endocrine And Diabetes Centre, King Hospital Abdulaziz Specialist Hospital Taif, Saudi Arabia \\ ${ }^{2}$ Infectious Diseases Department, Faculty of Medicine, Onsekiz Mart University, Turkey \\ ${ }^{3}$ Infectious Diseases and Clinical Microbiology, Bitlis State Hospital, Bitlis, Turkey
}

Coronavirus disease (COVID-19) pandemic currently 189.921.964 confirmed cases world wide; 4.088.281 continues with the case resulting in death [1]. SARS-CoV-2, the agent of COVID-19 disease, mainly affects the respiratory tract. The severity of the disease ranges from subclinical infections to diseases with severe symptoms that require hospitalization. There are a number of comorbid factors that are important in treatment and follow-up. It has been found that most patients with severe disease have an underlying disease, advanced age, obesity, cardiovascular disease, liver disease, kidney disease or malignancy [2-4]. Obesity has been found to be severely clinically related, especially in men; The risks of serious pneumonia, intubation and mortality are increased in obese malepatients [5-7]. Susceptibility to acute respiratory distress syndrome (ARDS), which is the primary cause of COVID-19 mortality, is significantly higher among individuals with obesity [6]. Individuals with obesity may also develop many underlying risk factors, including hypertension, dyslipidemia, type 2 diabetes (T2D), and chronic kidney or liver disease $[5,6]$. The disproportionate impact of COVID-19 in obese and overweight patients should not be considered surprising given the impact of obesity on pulmonary function. Obesity is associated with decreased expiratory reserve volume, functional capacity and respiratory system compliance. In patients with increased abdominal obesity, lung function is further compromised by reduced diaphragm movement in patients in the supine position and makes ventilation difficult causes [8]. In addition, increased inflammatory cytokines associated with obesity may contribute to obesity-related increased morbidity in COVID-19 infections [6-8].

Today, the proportion of overweight/obese individuals is more than $20 \%$ in almost all countries. It appears that there is a strong correlation between being an overweight or obese individual, their risk of hospitalization, their long-term follow-up in the hospital, and their need for treatment in intensive care units (ICUs). Some studies show that obese adults under 60 are more likely to be followed up in hospital. In the cohort examined in terms of the relationship between obesity and the severity of COVID-19, it was found that severe obesity (BMI $35 \mathrm{~kg} / \mathrm{m} 2$ ) was associated with ICU admission, and a history of heart disease and obesity (BMI $30 \mathrm{~kg} / \mathrm{m} 2$ ) was independently associated with IMV use [9-11].
Obesity can also disrupt medical treatments during COVID-19 infections. ACE inhibitors commonly used to treat hypertension; COVID-19 may be more severe in T2D patients, especially those with poorly controlled blood sugar [12]. In the United States and the UK, two-thirds of the population are overweight/obese, and it is important to understand the impact of COVID-19 treatments on obese patients and determine their long-term effectiveness [13].

Again, another side of the coin is the vaccine efficacy. Leptin resistance and low level of chronic inflammation associated with obesity, some cytokines and proteins secreted from adipose tissue and changes in the intestinal microbiota cause changes in the immune response, impairment of T cell responses and increased susceptibility to infections in obese individuals. Considering that COVID-19 vaccines may be less effective in populations with a high prevalence of individuals with obesity suggests that BMI should potentially be investigated for the efficacy and protection of vaccines $[14,15]$.

\section{References}

1. https://covid19.who.int/

2. Wang D, Hu B, Hu C, et al. (2020) Clinical characteristics of 138 hospitalized patients with 2019 novel coronavirus-infected pneumonia in Wuhan, China. JAMA 23: 1061-1069.

3. Chen N, Zhou M, Dong X, et al. (2020) Epidemiological and clinical characteristics of 99 cases of 2019 novel coronavirus pneumonia in Wuhan, China: A descriptive study. Lancet 395: P507-P513.

4. Wang T, Du Z, Zhu F, et al. (2020) Comorbidities and multi-organ injuries in the treatment of COVID-19. Lancet 395: e52.

5. Badr HS, Zaitchik BF, Kerr GH, et al. (2021) Unified real-time environmental-epidemiological data for multiscale modeling of the COVID-19 pandemic. medRxiv.

*Corresponding author: Emine Kübra Dindar Demiray, MD, Infectious Diseases and Clinical Microbiology, Bitlis State Hospital, Bitlis, Turkey, Tel: +90-5334743527

Accepted: September 09, 2021

Published online: September 11, 2021

Citation: Yaminuddin K, Alkan S, Demiray EKD (2021) COVID-19 and Obesity. Res Rev Infect Dis 4(1):149-150

Copyright: (C) 2021 Yaminuddin K, et al. This is an open-access article distributed under the terms of the Creative Commons Attribution License, which permits unrestricted use, distribution, and reproduction in any medium, provided the original author and source are credited. 
6. Popkin BM, Du S, Green WD, et al. (2020) Individuals with obesity and COVID-19: A global perspective on the epidemiology and biological relationships. Obes Rev 21: e13128.

7. Scheen AJ, Marre M, Thivolet C (2020) Prognostic factors in patients with diabetes hospitalized for COVID-19: Findings from the CORONADO study and other recent reports. Diabetes Metab 46: 265-271.

8. Stefan N, Birkenfeld AL, Schulze MB, et al. (2020) Obesity and impaired metabolic health in patients with COVID-19. Nat Rev Endocrinol 16: 341-342.

9. Kwong JC, Campitelli MA, Rosella LC (2011) Obesity and respiratory hospitalizations during influenza seasons in Ontario, Canada: A cohort study. Clin Infect Dis 53: 413-421.

10. Moser JS, Galindo-Fraga A, Ortiz-Hernández AA, et al. (2019) Underweight, overweight, and obesity as independent risk factors for hospitalization in adults and children from influenza and other respiratory viruses. Influenza Other Respir Viruses 13: 3-9.
11. Maccioni L, Weber S, Elgizouli M, et al. (2018) Obesity and risk of respiratory tract infections: Results of an infection-diary based cohort study. BMC Public Health 18: 271.

12. Cure E, Cure MC (2020) Angiotensin-converting enzyme inhibitors and angiotensin receptor blockers may be harmful in patients with diabetes during COVID-19 pandemic. Diabetes Metab Syndr 14: 349-350.

13. Neidich SD, Green WD, Rebeles J, et al. (2017) Increased risk of influenza among vaccinated adults who are obese. Int J Obes 41: 1324-1330.

14. Altmann DM, Boyton RJ (2020) SARS-CoV-2 T cell immunity: Specificity, function, durability, and role in protection. Sci Immunol 5: eabd6160.

15. Özalp B, Kürklü NS (2020) Obezite ve COVID-19. İzmir Katip Çelebi Üniversitesi Sağlık Bilimleri Fakültesi Dergisi 5: 211-214. 